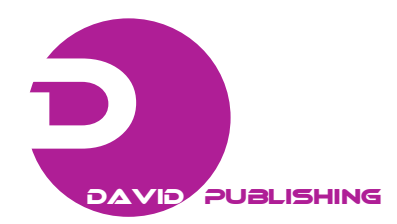

\title{
Utilization of DFIG on an Islanded Power Generation and Distribution System
}

\author{
Rene Rossi ${ }^{1}$ and Mohammad Masoum ${ }^{2}$ \\ 1. R. Rossi \& Associates, Kinglsey WA 6026, Australia \\ 2. Department of Electrical and Computer Engineering, Curtin University, Bentley WA 6102, Australia
}

Received: July 02, 2013 / Accepted: August 22, 2013 / Published: January 31, 2014.

\begin{abstract}
The utilization of wind generation equipment, such as DFIGs (double fed induction generators), interconnected to islanded power generation and distribution systems is investigated in order to determine their effects on the overall system operating characteristics and stability. The use of a stable power station (with high speed machines) will be critical in achieving fast and reliable transient response to network events, in particular, when large transient loads are expected on a continuous basis, i.e., industrial mining and mineral processing equipment. Simulation results of this paper assist in understanding how small power stations and wind generation equipment respond to large transients in an islanded network. In particular, detailed simulations and analyses will be presented on impacts of distributed wind generation units (1.5 MW DFIG) on the stability of a small weak network. The novelty of this paper is on detailed analyses and simulation of weak networks with interconnects DFIG's including their impacts on system stability under various transient operating conditions.
\end{abstract}

Key words: Grid system, weak network, DG (distributed generation), DFIG (double fed induction generator), DOL (direct on line), VVVF (variable voltage variable frequency), CFCT (critical fault clearing time).

\section{Introduction}

The application of wind generation systems are well understood and widely applied throughout much of the developed world. In most cases, these renewable resources are interfaced to solid/robust networks and compliant with all established requirements [1-6]. However, their impact on weak networks has not been thoroughly investigated in Refs. [7-9].

Given the ongoing drive to expand the use of DG (distributed generation) systems, the need to interface renewable energy resources such as wind generators to weak, radial and islanded networks is becoming apparent. The utilization of wind generation equipment interfaced to an islanded system could be considered to be in early stages of development. However, there is no doubt that these type of systems (small and islanded

Corresponding author: Rene Rossi, Ph.D., research field: the application of wind generation systems to weak networks. E-mail: rener@rossiassoc.com.au. power generation) interfaced with wind generation represent very weak networks which are considered to be complex with unique requirements. The need to include wind generation inertia constants forms a critical element of the analysis of weak networks [10-11].

An important issue that needs to be resolved in weak networks is how much generation can be attached to an islanded network and how the network would need to be operated under such conditions. Research on the application of wind generation to weak networks can be obtained in general terms, but not with detailed analysis at this stage [12-13]. The application of DFIG wind generation connected to islanded system has been rather limited as well.

This paper investigates important operating characteristics and stability issues associated with the connection of wind generation to an islanded network. The review will include system response to transient events required to limit power station instability and 
load effects (load acceptance and load rejection) on the network. Section 2 outlines the adopted methodology followed by reviews of issues that define a weak network in Section 3. The following two Sections 4 and 5 outline the network under consideration and network analysis while Section 6 presets simulation results followed by analyses (Section 7) and concluding remarks. This work is based on an existing network under consideration by a large industrial installation in WA, Australia.

\section{Methodology}

The adopted methodology to complete this research on an existing weak network is as follows:

- The starting point of this research work was to update the load flow model for the network under consideration. The information used in this computer model has been verified to represent the most accurate data for an existing network.

- Information on the power station generation equipment used has been obtained from the suppliers and the performance of the generators under transient events has been verified and modeled accordingly. Much of this information has been obtained from the suppliers of the sets (gas turbines and various reciprocating engine suppliers). The information on the wind generation equipment has also been obtained from the suppliers (GE-Schenectady, USA). Detailed dynamic model information on the DFIG units has been obtained and modeled using the ERACS-UDM software package [14]. The results of this model have been verified by comparing them with the suppliers' dynamic model results.

- The simulation events selected are based on what can be considered, but not limited to, the worst case scenarios such as transient events including machinery start/stop and fault events with the network.

\section{Issues Associated with Weak Networks}

A network can be considered weak due to a variety of practical limitations that would include:

- limited reactive capacity available for transient events and voltage control;

- very long transmission, sub-transmission and distribution overhead power lines;

- long radial power lines without backups;

- limiting CFCT (critical fault clearing times) on key transmission lines in order to reduce probability of instability under transient events such as large machinery start/stop, faults, etc.;

- remote generation installed at the end of heavily loaded transmission lines.

Each network under consideration must be carefully assessed in order to determine what makes it weak. Various papers have considered these issues [15-17]. However, the published research does not include detailed explanation, simulations and analysis of these events. Additional information on weak networks (stability based) can be found in various books [18-20].

\section{The Weak Network under Consideration}

In order to determine the viability of wind generation equipment connected to a weak network, the specific industrial network of Fig. 1 is considered.

The characteristics of this network are:

- The system represents an islanded network with a single power station to supply a mining and mineral processing operation that makes use of a large variety of industrial drives. Many of these drives will be DOL (direct on line) started while others will include VVVF (variable voltage variable frequency) drives including a single cyclo-converter based Sag Mill drive [21] that can operate up to $13 \mathrm{MW}$ of continuous load.

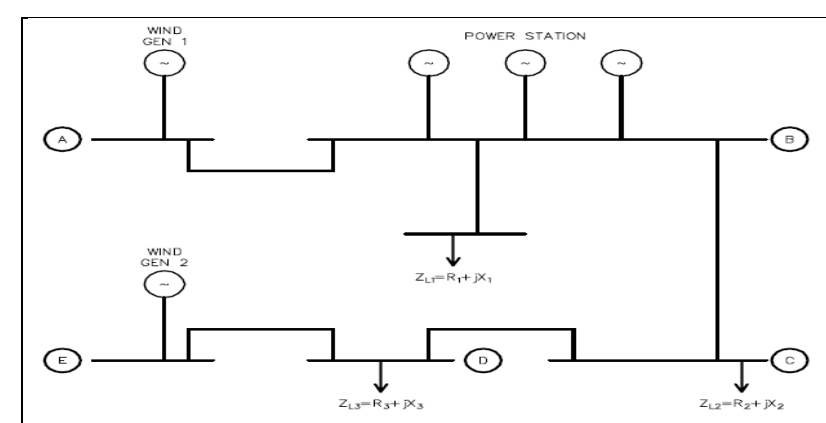

Fig. 1 Abbreviated single line diagram-Islanded power station \& distribution system with $2 \times(4 \times 1.5$ MW) DFIG wind generation. 
- The power station under consideration includes 4 $\times 15$ MVA gas turbine machines on an $n+1$ arrangement operating at $11 \mathrm{kV}$. This power station would interface with all load centers and would have no interconnections to utilities or other clients.

- The wind generation equipment would be installed in two separate locations of the network (at opposite ends of the network). The total capacity of the wind generation would not exceed $6 \mathrm{MW}$ at each end. This size is usually selected based on client's financial requirements.

- The wind generation unit used is the GE 1.5 MW DFIG unit as outlined in Fig. 2 [9]. This type of wind generation system has been selected in view of their availability and due to their ability to generate some reactive capacity even under no wind conditions. Please refer to Appendix for additional information on these units.

The use of small power generating stations is widely practiced in remote locations were utility systems interface is not possible. In remote sites, the availability of utility power is scarce forcing mining organizations to own and operate private power stations. With the advent of environmental legislation requiring the reduction of green gases footprint it has become necessary to consider the use of renewable energy sources such as wind generation.

\section{Network Analysis}

In order to establish the networks ability to maintain stability, we need to consider the most extreme transient

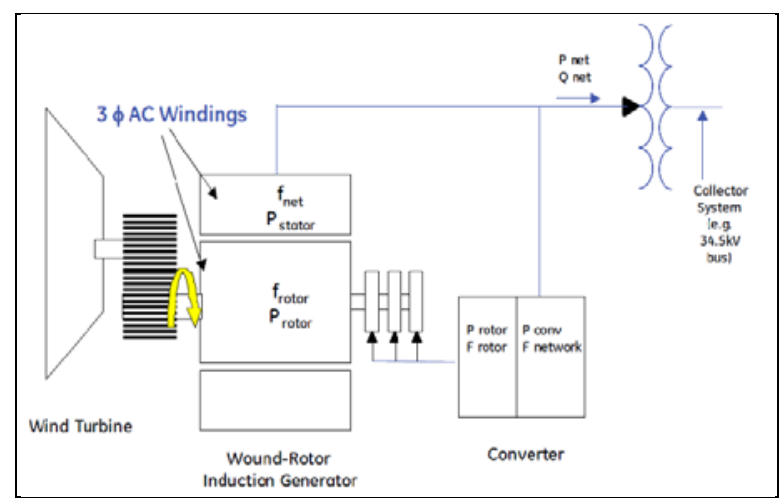

Fig. 2 DFIG arrangement. events that test the power station ability to accommodate such events. Consider the following typical events:

- load acceptance of the single largest load on site-13 MW Sag Mill start;

- load rejection of the single largest load on site-13 MW Sag Mill trip;

- single-phase fault on the $66 \mathrm{kV}$ distribution network;

- three-phase fault on the $66 \mathrm{kV}$ distribution network.

Testing of these events would take place while the wind generation system is active and producing the maximum amount of power it has been designed to achieve.

The single largest contribution to any fault will come from the power station and not the wind generation system, although ride through capability is expected. Thus:

where,

$$
\begin{gathered}
S_{G}=P_{G}+j Q_{G} \gg S_{w}=P_{w}+j Q_{w} \\
S_{G}^{\prime \prime} \gg S_{W}^{\prime \prime}
\end{gathered}
$$

$P_{G}$ - Power station active power (MW);

$Q_{G}$-Power station reactive power (MVAR);

$P_{w}$-Wind generation system active power (MW);

$Q_{w}$-Wind generation system reactive power (MVAR);

$S_{G}$-Power station apparent power (MVA);

$S_{w}$-Wind generation apparent power (MVA);

$S_{G}^{\prime \prime}$-Power station fault level (MVA);

$S_{W}^{\prime \prime}$-Wind generation fault level (MVA).

The fault contribution in this case will be dependent on the amount of generation operational at the power station considering that the wind generation fault contribution will be low irrespective. In addition, the inertia offered by the generation sets used at the power station will have an impact on $S_{G}^{\prime \prime}$.

The amount of wind generation to be used in this site would amount to no more than $50 \%$ of the total load, although this could be further limited by the technology used at the power station (gas turbines vs. reciprocating engines and their relevant capacities). 
When considering multiple machines, each machine can be expressed in terms of the machine's internal voltages [19] or:

$$
\begin{gathered}
S_{e i}{ }^{*}=E_{i}{ }^{*} I_{i} \\
P_{e i}=R\left[E_{i}{ }^{\prime *} I_{i}\right] \\
I_{i}=\sum_{j=1}^{m} E_{j}{ }^{\prime} Y_{i j}
\end{gathered}
$$

where:

$E_{i}{ }^{\prime *}$-Voltage output of the $i$ th machine;

$I_{i}$ - Current output of the $i$ th machine;

$Y_{i j}$-Elements of the faulted reduced bus admittance matrix.

In the polar form, it obtains:

$$
E_{i}{ }^{\prime}=\left|E_{i}{ }^{\prime}\right| \delta \text { and } Y_{i j}=\left|Y_{i j}\right| \theta_{i j}
$$

Substituting Eq. (6) into Eq. (3):

$$
P_{e i}=\sum_{j=1}^{m}\left|E_{i}^{\prime}\right|\left|E_{j}^{\prime}\right|\left|Y_{i j}\right| \cos \left(\theta_{i j}-\delta_{i}+\delta_{j}\right)
$$

Based on Eq. (6), the following swing equation is obtained that includes multiple machines:

$\frac{H_{i}}{2 \pi f_{0}} \frac{d^{2} \delta_{i}}{d t^{2}}=P_{m i}-\sum_{j=1}^{m}\left|E_{i}^{\prime}\right|\left|E_{j}^{\prime}\right|\left|Y_{i j}\right| \cos \left(\theta_{i j}-\delta_{i}+\delta_{j}\right)(8)$

The general solution to the above swing equation is: $\delta=\delta_{0}+\left(\Delta \delta /\left\{\sqrt{\left(1-\delta^{2}\right)}\right) * e^{-\vartheta \omega_{n}^{2} \tau} \sin \left[\omega_{d} t+\theta\right]\right\}(9)$ $\left.f=f_{0}+\left\{\frac{\omega_{n} * \Delta \delta}{2 * 180}\right)\left(\sqrt{\left(1-\delta^{2}\right)}\right) * e^{-\vartheta \omega_{n}^{2} \tau} \sin \left(\omega_{d} t\right)\right\}$

When this swing equation is applied to an islanded power station generator, it will be quite effective in establishing the level of rotor angle that can be expected under various transient events such as faulted system, load rejections and load acceptance for large drives etc..

In the case where you have two or more sets of machines as could be described in this case the swing equation can be established as Ref. [19]:

$$
\frac{H_{n}}{\pi f_{0}} \frac{d^{2} \delta_{n}}{d t^{2}}=P_{M_{n}}-\sum_{j=1}^{m}\left|E_{n}^{\prime}\right|\left|E_{j}^{\prime}\right|\left|Y_{n j}\right| \cos \left(\theta_{n j}-\delta_{n}+\delta_{j}\right)(11)
$$

where:

$$
\frac{H_{n}}{\pi f_{0}} \frac{d^{2} \delta_{1}}{d t^{2}}=P_{M_{n}}-P_{e_{n}}
$$

And:

$\frac{H_{k}}{\pi f_{0}} \frac{d^{2} \delta_{k}}{d t^{2}}=P_{M_{k}}-\sum_{j=1}^{m}\left|E_{k}^{\prime}\right|\left|E_{j}^{\prime}\right|\left|Y_{k j}\right| \cos \left(\theta_{k j}-\delta_{k}+\delta_{j}\right)(13)$

Thus:

$$
\frac{H_{k}}{\pi f_{0}} \frac{d^{2} \delta_{2}}{d t^{2}}=P_{M_{k}}-P_{e_{k}}
$$

In this case, the following information is relevant:

$$
\begin{aligned}
\left|E_{k}^{\prime}\right| & =\left|E_{k}^{\prime}\right|\left\llcorner\delta_{k}\right. \\
\left|E_{j}^{\prime}\right| & =\left|E_{j}^{\prime}\right|\left\llcorner\delta_{j}\right. \\
\left|Y_{k j}\right| & =\left|Y_{k j}\right|\left\llcorner\theta_{k j}\right.
\end{aligned}
$$

The same concept applies to the network swing equation.

If we apply the following abbreviations:

$$
\begin{aligned}
& M_{n}=\frac{H_{n}}{\pi f_{0}} \\
& M_{k}=\frac{H_{k}}{\pi f_{0}} \\
& \delta=\delta_{n}-\delta_{k}
\end{aligned}
$$

We obtain a combined swing equation for the two machine problem [18]:

$$
\frac{M_{n} M_{k}}{M_{n}+M_{k}} * \frac{d^{2} \delta}{d t^{2}}=\frac{\left(M_{k} P_{M_{n}-} M_{n} P_{M_{k}}\right)-\left(M_{k} P_{e_{n}-} M_{n} P_{e_{k}}\right)}{M_{n}+M_{k}}
$$

In this case, we have two clearly defined entities [18]:

$$
\begin{gathered}
P_{i}=\frac{\left(M_{k} P_{M_{n}-} M_{n} P_{M_{k}}\right)}{M_{n}+M_{k}} \\
P_{u}=\frac{\left(M_{k} P_{e_{n}} M_{n} P_{e_{k}}\right)}{M_{n}+M_{k}}
\end{gathered}
$$

Inertia constant $(H)$ for typical gas/diesel power generation equipment has been obtained for the power station machines under consideration.

where:

$H$-Per unit inertia constant;

$f_{o}$-Frequency;

$\delta$-Electrical power angle;

$P_{m}$-Mechanical power;

$P_{e}$-Electrical power.

Eq. (11) clearly indicates that the machine inertia selected will have a large impact on the power station's ability to handle transient events as previously described (high speed vs. low speed machines).

The wind turbines will contribute to voltage stability (ride through) for a limited time based on their location on the network and the type of transient under consideration.

In addition to these parameters, it is also essential to understand that the voltage levels obtained under 
transient events will have a large impact on the networks ability to manage transients. Voltage levels in the power station, for example, will need to remain as stable as possible under transient events, with some contribution from the wind generation equipment (i.e., ride through capabilities). Low voltage levels during transient events will force operation of protection relays and the risk of blackout. In addition, the use of low CFCT settings will further limit network stability and may force early tripping of protection relays.

The addition of wind generation to the network will also include swing equations that will yield different $H$ values for each DFIG unit and a group $H$ for all wind generation equipment [11]. The dynamic model does not include such a calculation at this stage.

With weak networks, the margin between stable and unstable system is rather limited implying that any fault outside a single-phase fault will bring instability if not cleared quickly. Each network under consideration will have a unique set of values that will give unique results. When the utilization of wind generation is applied to weak networks consideration for the overall operational performance of the network must be carefully understood. For any network under transient fault events, it will be necessary to consider the system/equipment impedances to establish the largest contributor to the fault.

\section{Simulations}

The network of Fig. 1 has been modeled using ERACS software in great detail. Wind generation has been added as a separate arrangement that interconnects the power station via a dedicated $66 \mathrm{kV}$ line. The following simulations have been completed:

- load acceptance of the $13 \mathrm{MW}$ drive;

- load rejection of the $13 \mathrm{MW}$ drive on a trip event (instantaneous);

- a single-phase fault on the $66 \mathrm{kV}$ distribution network (away from the power station);

- a three-phase fault on the $66 \mathrm{kV}$ network (away from the power station).
The wind generation included as part of the network has been based on a $12 \mathrm{MW}$ arrangement $(2 \times(4 \times 1.5)$ MW DFIG based units). The critical objective in these models is to determine the networks ability to maintain stability under each of the events stated. Information on the generation sets used and the wind generation units under consideration can be seen in Appendix 1.

\subsection{Load Acceptance Transients}

Figs. 3 and 4 show the transient response for the starting of a 13 MW cyclo-converter mill drive. Start-up duration period is over $60 \mathrm{~s}$ to full RPM. The process involves energizing two harmonic filters with 2 $\times$ 4.0 MVAR capacitor each prior to starting the mill drive and disconnecting these once the drive has reached full RPM's. This process initiates $0.5 \mathrm{~s}$ after the start of simulation.

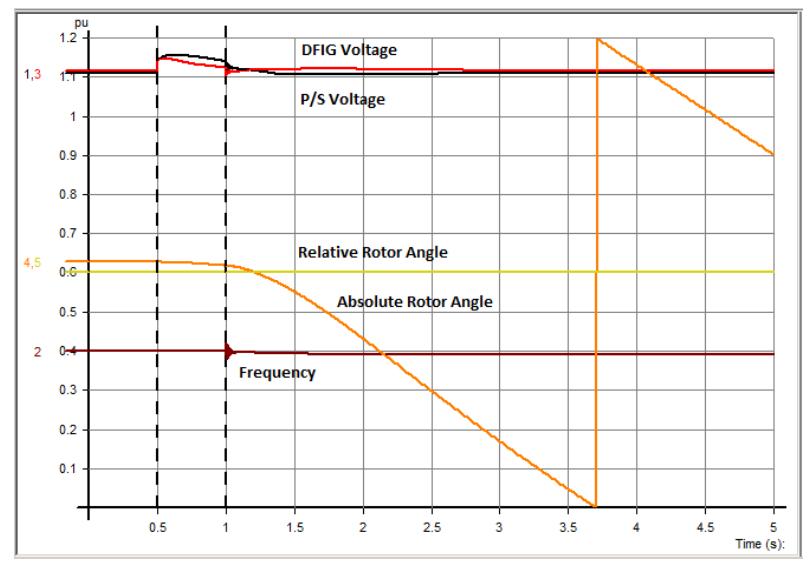

Fig. 3 The 13 MW cyclo-converter based Sag Mill startup stability voltage and rotor angle responces.

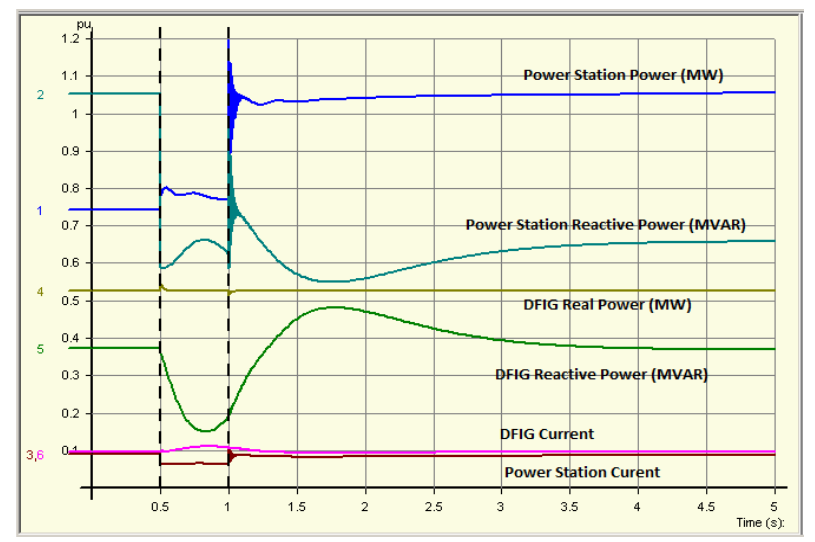

Fig. 4 The 13 MW cyclo-converter based Sag Mill startup transient stability including the general power output transient chart. 
The response indicates that the first stage of harmonic filter energizing is $0.5 \mathrm{~s}$ prior to mill start, followed by the starting of the Sag Mill. On closure of the filters a clear increase in busbar voltage is obtained. Most of the reactive compensation required at the starting stage is shared by both power sources (PS and DFIG) establishing good ride-through capacity.

The simulation shows the first $4 \mathrm{~s}$, a period that instills the largest transient on the start-up. The use of high inertia machines helps to maintain stability of the network on accepting such a large machine start-up and the addition of wind generation, which contributes with reactive capacity and assists in the process of start-up as well.

\subsection{Load Rejection Transients}

While the start-up of the mill has minimal transient issues with the network, the actual tripping of the Sag Mill drive feeder would represent a larger risk for the network. Figs. 5 and 6 show the outcome of tripping the feeder circuit breaker that supplies the cyclo-converter unit. This, in effect, would represent a fault on the feeder system to the mill during normal operation.

The rejection of such a load (feeder trip) represents a loss of some $45 \%$ of the operation load and the generation sources would quickly stabilized the transient. Most of the load change is accommodated by the power station as the wind generation units provide power based on the wind availability only. In this case, the inertia of the power station machines will play a significant role in stabilizing the network.

The use of power generation machines with low inertia would offer a different result. In most cases, the power station would not be able to compensate for such transients and would result in total blackout.

\subsection{Single-Phase Fault at 66 kV (Victory Substation)}

A further transient model can be seen in Figs. 7 and 8 that show a single line to ground fault on the $66 \mathrm{kV}$ system. In this case, the power station and wind

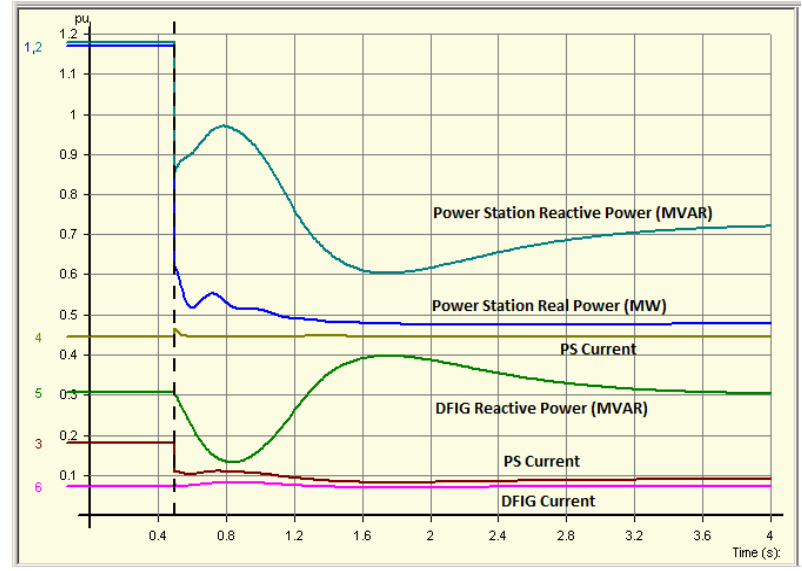

Fig. 6 Load rejection transient stability model of a $13 \mathrm{MW}$ Sag Mill including the general power output transient chart.

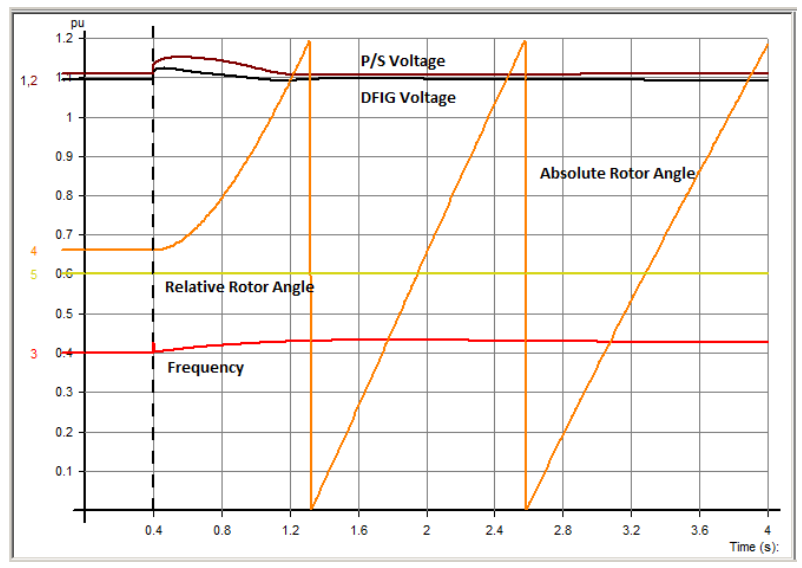

Fig. 5 Load rejection transient stability model of a $13 \mathrm{MW}$ Sag Mill including the general power output transient chart.

generation system maintains a high degree of stability without causing a blackout at the power station (good ride-through capability).

The $66 \mathrm{kV}$ system, in this case, is rather sparse and prone to lightning strikes. It represents the backbone of the power distribution system. The design is radial with long sections that make it quite weak in places. A fault of $200 \mathrm{~ms}$ duration is applied and cleared (typical event).

By the result of this simulation (Figs. 7 and 8), it is evident that the majority of the power swing is seen by the power station, but the DFIG wind turbines do assist in maintaining stability. The DFIG stations provide enough reactive compensation to assist the power station in maintaining stability (ride-through capability). 


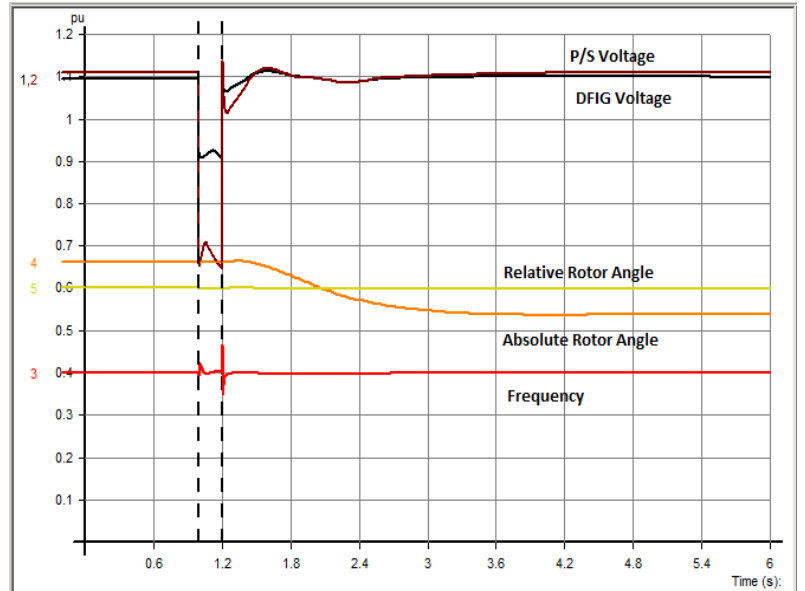

Fig. 7 Transient stability response to a single-phase fault applied to a section of a $66 \mathrm{kV}$ overhead power line with rotor angle and voltage system responses.

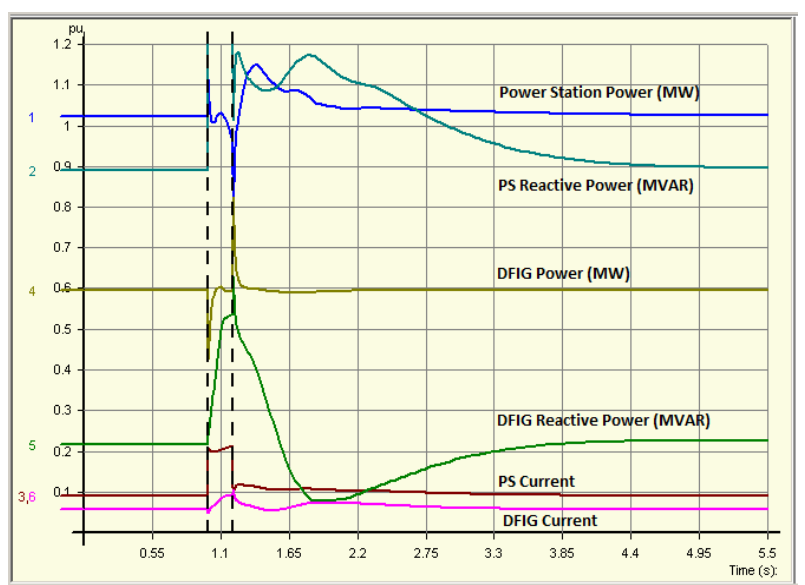

Fig. 8 Transient stability response to a single-phase fault applied to a section of a $66 \mathrm{kV}$ overhead power line forming part of the distribution network.

\subsection{Three-Phase Fault at $11 \mathrm{kV}$ Bus}

An additional simulation has been conducted where a three-phase fault is simulated on an $11 \mathrm{kV}$ switchboard busbar in one of the mining operations. The fault duration has been set for $200 \mathrm{~ms}$ between commencement of fault event and clearing of fault. Refer to Figures 9 and 10, the overall response of a three-phase fault at $11 \mathrm{kV}$ is rather similar to that of a single-phase fault at $66 \mathrm{kV}$, although this would require additional reactive compensation during the fault event.

\section{Analysis}

A variety of simulations with varying wind generation penetration for the weak network of Fig. 1 have been

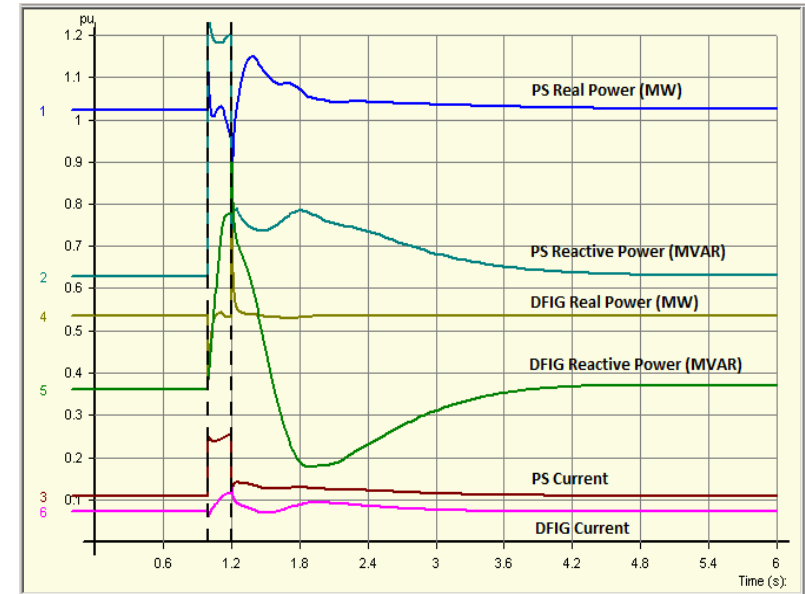

Fig. 9 Transient stability model of a three-phase fault applied to an $11 \mathrm{kV}$ switchboard forming part of the general HV distribution system.

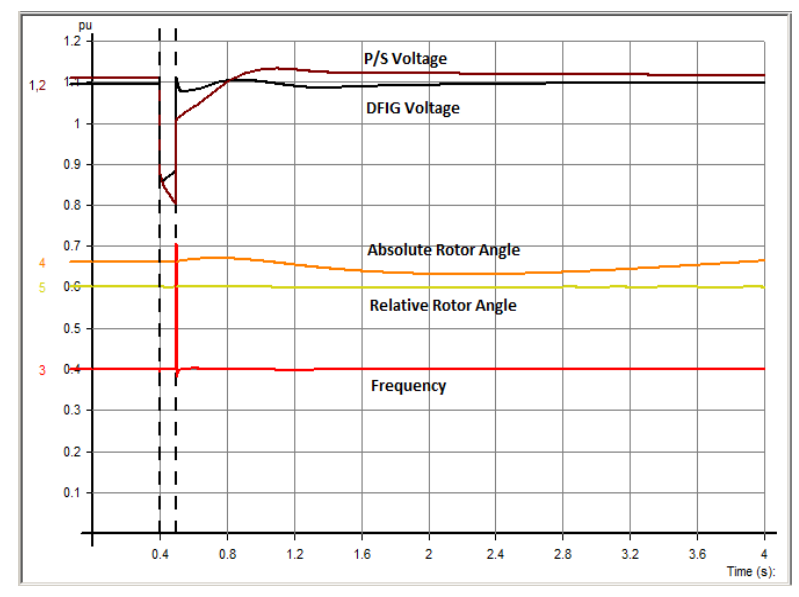

Fig. 10 Transient stability model of a three-phase fault applied to an $11 \mathrm{kV}$ switchboard forming part of the general HV distribution system with rotor angle and voltage system response.

conducted with the worse possible transient events that could take place (load based). The following can be concluded from these simulations:

- It is essential to ensure that the wind generation system must be interfaced such that it will assist in stabilizing the network when transients take place. In this case, it has been necessary to split the wind generation equipment into two separate groups installed away from each other (at the end of each section of the network). The power station has been located close to the largest load and was the single largest transients can take place. The ability to split the wind generation installations allows for larger wind penetration considering that each connection still 
limits possible instability of the complete network in the event of a wind generation interface loss.

- The fault simulations (at $66 \mathrm{kV}$ and $11 \mathrm{kV}$ buses) make use of a maximum duration of 200 msec. This is based on protection relays settings used on site, but would need to be re-considered once such an installation is completed. At this stage, this fault duration can be considered to be on the high side as CFCT requirements with islanded systems are generally low and quite restrictive. A relevant protection coordination review would be essential.

- The power station will, in most cases, absorb most of the transients that could take place. Yet, the wind generation does assist in stabilizing the network when under fault or large transient. The wind turbine dynamic model used allows for quick reactive power compensation from all units, thus assisting with network voltage stability. In this paper, the dynamic model has been thoroughly tested to ensure this reactive power response is present.

- The ability of the network to provide the necessary power to start large machines such as Sag Mills will be dependent on how fast the drive achieves full RPM's and ensuring that sufficient reactive capacity is available. The use of wind generation (when fully operational) will assist with this requirement, although the application of a cyclo-converter system with a slow rise time limits the reactive compensation required.

- The amount of wind generation that will be required to assist the power station in its ability to meet the load or transient events would be dependent on how much generation is available in the power station. It will also have some dependence on the expected largest size of the transient. In general, wind generation should not be relied on to start large loads without sufficient power station capacity. The wind generation will be more effective in assisting with fault transient events than with load acceptance events.
- Similar simulations have been completed using reciprocating engines as part of the power station, but the result during transient events is far from acceptable irrespective of wind generation capacity available at the time. The use of low RPM machines in islanded operations with large transient loads will demand a large spinning reserve at the power station in order to manage load changes or faults. Wind generation equipment will not be viable in this case.

- While the simulations conducted in this case pertain to a specific network, it will be essential to understand that each network of similar characteristics will require its own analysis and determination of where wind generation should be installed. The amount of wind generation shall need to be assessed accordingly as well.

- The single largest risk to system stability can occur when the wind generation is fully operational and one or more power station generators are disconnected and turn off. In the event that a leg of the wind generation interface trips, it could lead to load shedding requirements in the first instance until a power station generator can be synchronized.

\section{Conclusions}

This paper has investigated the impacts of wind generation equipment such as DFIGs on system operating characteristics and stability of weak islanded networks. The simulations conducted have been based on the potential installation of such a system in a remote mining operation. The results obtained present a network that could be quite effective in meeting all the projected loads for an isolated operation, but will also meet the transient events that can be expected in the mining operation. The power station would need to be designed to meet the operations load (no wind situation), but it is evident that the use of large wind generation on-site would assist with transient events stability as has been demonstrated by the results of the modeling. Splitting the wind generation unit installation will further limit any potential power 
station instability in the event of wind generation interface loss.

\section{Acknowledgments}

Completion of this work has been possible due to the assistance of Mr. Lambourne and Mr. Langdon from SIGMC. In addition, the assistance of ERA technologies with the UDM model of the 1.5 MW DFIG Wind Generation units has been invaluable [9].

\section{Further Research}

Additional studies are to be performed on protection issues associated with the interface of wind generation to weak networks, specifically, on how to adapt wind generation to an already tightly controlled protection settings on weak networks. The need to avoid significant system instabilities due to large transients is paramount with such networks.

Most of this research work is still oriented towards network stability and not necessarily towards the performance of wind generation and its capability when under minor transients.

\section{References}

[1] Z. Chen, J.M. Guerrero, F. Blaabjerg, A review of the state of the art of power electronics for wind turbines, IEEE Trans. Power Electron. 24 (8) (2009) 1859-1875.

[2] M. Mohseni, S. Islam, M.A.S. Masoum, Impacts of symmetrical and asymmetrical voltage sags on DFIG-based wind turbines considering phase-angle jump, voltage recovery, and sag parameters, IEEE Trans. Power Electron. 26 (5) (2011) 1587-1598.

[3] M. Mohseni, S. Islam, M.A.S. Masoum, Enhanced hysteresis-based current regulators in vector control of DFIG wind turbines, IEEE Trans. Power Electronics 26 (4) (2011) 223-234.

[4] M. Mohseni, S. Islam, Transient control of DFIG-based wind power plants in compliance with the Australian grid code, IEEE Trans. Power Electronics 27 (6) (2012) 2813-2824.

[5] P.S. Flannery, G. Venkataramanan, A fault tolerant doubly fed induction generator wind turbine using a parallel grid side rectifier and series grid side converter, IEEE Trans. Power Electron. 23 (3) (2008) 1126-1134.
[6] J. Yao, H. Li, Y. Liao, Z. Chen, An improved control strategy of limiting the DC-link voltage fluctuation for a doubly fed induction wind generator, IEEE Trans. Power Electron. 23 (3) (2008) 1205-1213.

[7] R. Piwko, N. Miller, J. Sanchez-Gasca, X. Yuan, R. Dai, J. Lyons, Integrating large wind farms into weak power grids with long transmission lines, in: 2005 IEEE/PES, Transmission and Distribution Conference and Exhibition, Asia and Pacific, Dalian, China, 2005, pp. 1-7.

[8] E. Muljadi, C.P. Butterfield, B. Parsons, A. Ellis, Effect of variable speed wind generator on stability of a weak grid, IEEE Trans. Energy Conversion 22 (1) (2007) 19-36.

[9] N.W. Miller, J.J. Sanchez Gasca, W.P. Price, R.W. Delmerico, Dynamic modeling of GE 1.5 and 3.6 MW wind turbine-generators for stability simulations, in: 2003 IEEE/PES General Meeting, Toronto, Canada, 2003, pp. 1977-1983.

[10] M.P. Comech, D. Garcia, M. Sanz, J.M. Garcia, M.G. Garcia, Validity range of wind turbine models, in: ICREPQ’04, Barcelona, Mar. 31-Apr. 2, 2004.

[11] A.G. Rodriguez, A. Rodriguez, M.B. Payan, Estimating wind turbines mechanical constants, in: ICREPQ'07, Sevilla, 2007.

[12] M. Rasmussen, H.K. Jorgensen, Current technology for integrating wind farms into weak power grids, in: IEEE/PES Transmission and Distribution Conference and Exhibition: Asia and Pacific, Dalian, China, 2005.

[13] J. Wiik, J.O. Gjerde, T. Gjengedal, Impacts from Large Scale Integration of Wind Farms into Weak Networks, IEEE 0-7803-6338-8/00, 2000.

[14] Sustainable Energy Development Office, Government of Western Australia Home Page, www1.sedo.energy.wa.gov.au/pages/rrpgp.asp.

[15] M. Rasmussen, H.K. Jorgensen, Current technology for integrating wind farms into weak power grids, in: 2005 IEEE/PES Transmission and Distribution Conference and Exhibition: Asia and Pacific, Dalian, China, 2005, pp.1-4.

[16] Wind Power in Power Systems, in: T. Ackerman (Ed.), Wiley Publishers, Sept. 2005.

[17] ERACS Software, ERA Technologies Ltd. Home Page, www.eracs.co.uk.

[18] E.W. Kimbark, Power System Stability-Vol \#1, IEEE Press, 1995. (Chapters 1-6)

[19] H. Saadat, Power System Analysis, McGraw Hill Higher Education, 2002. (Section 11.5)

[20] P. Kundur, Power System Stability and Control, McGraw Hill, 1994. (Chapter 13)

[21] S.A. Greer, Selection criteria for SAG Mill drive systems, IEEE Trans. Industry Applications 26 (5) (1990) 901-908. 


\section{Appendix 1}

The wind generation units used in this paper is the GE 1.5 MW DFIG based wind turbine (Fig. 2). Detailed information on the dynamic model for this particular wind generation unit has been obtained from GE in Schenectady, NY and has been modeled into the ERACS UDM software [17].

The ERACS - Power system software package has been selected to perform such system studies considering the followings points: The software has been used by the mining operation for many years and is well understood by most electrical personnel.

The software has the ability to dynamically model the DFIG wind turbine as prescribed by GE. All performance test conducted on the model was corroborated by the results obtained by the GE model, which has been done using PSSE software.

The transient stability module used by ERACS easily incorporates the wind turbine dynamic model and clearly outline the results.

Information on the dynamic model used was supplied by GE representatives [9] and is based on the feedback arrangement seen in Fig. 11. The dynamic model of the wind turbine takes into consideration the networks voltage, network frequency, wind speed and blade angle. However, this model does not take into consideration the inertia constant $H$ as compared to the power station generators.

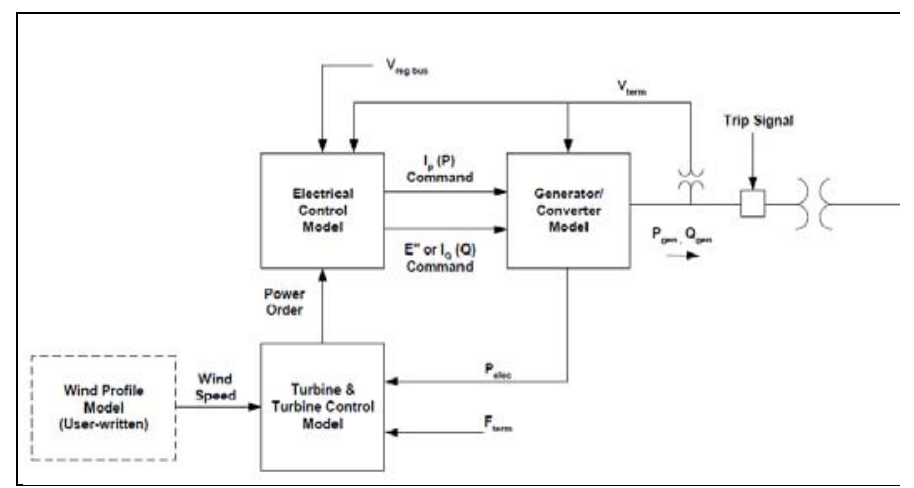

Fig. 11 GE 1.5 MW DFIG wind generation block diagram. 